\title{
Indicadores físico-químicos y microbiológicos en la remoción de contaminantes de efluentes de procesos de tratamiento segundarios de aguas residuales agroindustriales y domésticos
}

\author{
Catalina Vargas Meneses
}

\section{RESUMEN}

La investigación trabajo con aguas residuales que se encontraban aún en proceso de descontaminación, no se trabajó ninguna muestra a efluentes. Las muestras de aguas residuales analizadas proceden de tres distintos tipos de sistemas de tratamiento, todas las muestras se tomaron de la sección del proceso secundario del tratamiento. Se caracterizaron los tipos de aguas residuales de las aguas crudas del campo en el laboratorio y una porción de la muestra se dispuso en reactores anaerobios y aerobios en condiciones de laboratorio para homogenizar las características de cada agua, para un posterior análisis de agentes microbiológicos que pudieran contener.

La primera etapa consistió en la caracterización físico-química de las muestras de aguas residuales de efluentes de un tratamiento secundario y de los reactores del laboratorio; los resultados se compararon con los estándares costarricenses, para verificar funcionamiento de cada sistema y posterior a esta caracterización se dispusieron diferentes medios de cultivos para determinar coincidencia de microrganismos que pudieran favorecer el proceso de descontaminación, de las aguas crudas y de las tratadas en los reactores del laboratorio.

Palabras clave: Análisis físico-químicos, aguas residuales, Beneficio, Tenería, Condominio, pseudomonas taetrolens.

\begin{abstract}
The investigation worked with wastewater that was still in the process of decontamination. No effluent sample was processed. The analyzed wastewater samples come from three different types of treatment systems. All samples taken were from the secondary treatment process. The types of wastewater from the raw water were characterized and a portion of the sample was placed in anaerobic and aerobic reactors. The waters of the in laboratory conditions are to homogenize the characteristics of each water, and a subsequent analysis of microbiological agents that they may contain.

The first stage consisted of the physical-chemical characterization of the wastewater samples from effluents from a secondary treatment and from the laboratory reactors; The results were compared with the Costa Rican standards to verify the operation of each system. Finally, different culture media were available to determine the coincidence of microorganisms that could favor the decontamination process, of the raw waters and of the treated waters in the laboratory reactors.
\end{abstract}

Key words: Physic-chemical analysis, wastewager, Benefit, Tannery, Condominium, pseudomonas taetrolens.

\section{Introducción}

En general se espera que los sistemas de tratamientos generen productos líquidos con una carga química que sea significativamente menor a la original. Suele relacionarse con este tema el éxito del funcionamiento de la planta de tratamiento, pero no siempre se tiene la herramienta del análisis físico-químico, durante los 
procesos de operación y manejo de los sistemas de descontaminación que permitan mejorar el rendimiento de los sistemas. (Rodríguez, 2002)

Es así que la información de la calidad físico-química de las aguas residuales es de gran importancia, no solo para conocer la carga contaminante que los efluentes tienen, sino también, para determinar el funcionamiento de los tratamientos, especialmente en los procesos secundarios que se llevan a cabo en los sistemas de tratamiento y mejoras que se puedan implementar e incluso hasta la proyección de implementación de otras etapas de nivel de tratamiento terciario para descontaminar y mejorar aún más la calidad del vertido. (Allen, 1996)

En Costa Rica se han estudiado y regulan las aguas residuales de origen agroindustrial y doméstico en diversas investigaciones, pero en casi todos los estudios se indica que es preciso mayor recolección de parámetros físico-químicos sobre la eficiencia química de los tratamientos secundarios, es justamente en este tipo de efluentes que se realizó este estudio, sobre todo aquellos que han tomado mayor auge en la economía local. Por ejemplo, al suroeste del Valle Central del país, cobran importancia las actividades de curtiembre o tenería (procesos de curtido de pieles), fincas cafetaleras y complejos urbanísticos. (Vidal, 2006)

Si todos los inmuebles donde se generen aguas residuales cuentan con los sistemas de tratamiento que como parte de sus procesos incluyen una sistematización controlada durante todo el proceso de descontaminación y velan porque todo se haga conforme a lo diseñado, pero no mantienen un control eficiente de la calidad físico-químicas necesarias para asegurar que el agua que se vierte después del proceso de depuración cumple con los estándares de calidad, subutilizan los procesos de descontaminación con los que cuentan. $\mathrm{Si}$ a esto se le suma el hecho de la falta de acciones mínimas de mantenimiento, que muchas veces pretenden sean sistemas auto gestionables y se omite la debida revisión periódica, además de limpieza pertinente, y se espera a realizar intervenciones hasta que exista un daño, esto influirá sin lugar a duda en la calidad del efluente que se vierta de ese sistema al cuerpo receptor. (Vargas, 2010)

Sumado a la calidad físico-química de los vertidos, no hay que dejar de lado las pruebas bacteriológicas, que a pesar de ser un tema árido y de poca información, pueden influir en la salud y contaminación del ambiente, dado que si se pretende crear ciclos de reuso del agua es necesario mantener los sistemas de tratamiento de agua en óptimas condiciones, para evitar poblaciones de microorganismos que puedan perjudicar la vida de las personas si llegan a estar en contacto con el agua tratada, o también en el caso de los vertidos para para no afectar la dinámica microbiana de los cuerpos receptores, esto a pesar de que en Costa Rica la consideración en la normativa de los parámetros microbiológicos es escasa.

Como consecuencia de todo lo antes mencionado, en el país se ha venido procurando incrementar la regulación en los parámetros de las aguas tratadas, ya que en los reglamentos actuales no se toma en cuenta el funcionamiento de los sistemas, solamente en el cumplimiento de parámetros de vertido) de los sistemas de tratamiento de aguas residuales; sin embargo, los estudios solicitados por el Ministerio de Salud, Acueductos y Alcantarillados entre otras entidades gubernamentales, para determinar el buen funcionamiento de las plantas, son poco descriptivos, dado que los únicos parámetros en los que se enfocan los reglamentos son físico-químicos y, en cuanto a pruebas microbiológicas, el Reglamento de Vertido y Reuso de Aguas Residuales solicita en los ensayos los coliformes fecales, que no especifican la calidad del agua o el funcionamiento del sistema en sí. (RVRAR, 2006)

La importancia de realizar un análisis bacteriológico en los procesos tratamiento de las aguas residuales, permite determinar la predominancia de los microorganismos que se generan en el sistema; con esto pueden ser clasificados y determinar cuáles de ellos sería aconsejable mantener a lo largo del proceso de descontaminación para mejorar la calidad del agua que es vertida a los cuerpos de agua o alcantarillados sanitarios; de igual manera, enfatizar en los procesos que deben eliminar microorganismos que perjudican el bienestar de los seres vivos, especialmente los humanos, es claro que la determinación de la población microbiana total en aguas residuales donde hay una presencia importante es complejo y caro, además de 
contrastar con uso de indicadores, pero dependiendo de los procesos es valioso hacer el esfuerzo para mejorar los efluentes. (Allen, 1996)

Este proyecto pretende buscar la coincidencia de microorganismos que favorecen la remoción de contaminantes en las aguas residuales tratadas en diferentes tipos de sistemas de tratamiento (industrial, beneficio de café y aguas negras de urbanización), mediante una caracterización de los efluentes; con esto se podría plantear técnicas de estandarización, recomendaciones y prácticas en las instalaciones, que ayudarían a incrementar su eficiencia; además de mejorar la calidad de las aguas vertidas que posteriormente puedan reusarse para diferentes fines, e incluso ayudar al medio del cuerpo de agua donde se viertan.

\section{Materiales y Métodos}

La investigación se llevó a cabo a partir de tres tipos de agua, correspondientes a una Tenería en Alajuela, a un Beneficio de café en San Antonio de Belén y las aguas residuales domésticas de un condominio en Pozos de Santa Ana; se buscó que las áreas geográficas de ubicación de las fuentes estuvieran climáticamente relacionadas dentro de la misma zona de vida para que las comparaciones que se hicieran de los parámetros de los análisis fueran lo más similares geoespacialmente y así poder inter relacionar los resultados que se pudiesen obtener de los análisis de caracterización.

Se planteo estratégicamente las recolecciones de las muestras para el mismo día en los tres puntos de investigación, por lo que el muestreo que se realizó se hizo de la siguiente manera:

CUADRO 1.

Metodología del trabajo

\begin{tabular}{|c|c|c|c|c|c|c|}
\hline Actividad & $\begin{array}{c}\text { Tipos de } \\
\text { Agua }\end{array}$ & $\begin{array}{l}\text { Campos } \\
\text { de } \\
\text { Cultivo }\end{array}$ & $\begin{array}{l}\text { Reactor } \\
\text { Anaerobio }\end{array}$ & $\begin{array}{c}\text { Tiempo } \\
\text { (días) }\end{array}$ & $\begin{array}{l}\text { Reactor } \\
\text { Aerobio }\end{array}$ & $\begin{array}{c}\text { Tiempo } \\
\text { (días) }\end{array}$ \\
\hline $\begin{array}{l}\text { Toma de muestra } \\
\text { en los reactores } \\
\text { biológicos de las } \\
\text { plantas de } \\
\text { tratamiento }\end{array}$ & $\begin{array}{c}3 \\
\text { Tenería } \\
\text { Beneficio } \\
\text { Condominios }\end{array}$ & & & & & \\
\hline $\begin{array}{l}\text { Montar campos } \\
\text { de cultivos de las } \\
\text { aguas residuales }\end{array}$ & 3 & $\begin{array}{c}2 \\
\text { c/muestra } \\
\text { Total }=6\end{array}$ & & & & \\
\hline \begin{tabular}{lr}
\multicolumn{2}{l}{ Dividir muestra } \\
de agua & para \\
reactores & en \\
condiciones & de \\
laboratorios. &
\end{tabular} & 3 & & $\begin{array}{c}\text { Tenería } \\
\text { Beneficio } \\
\text { Condominios }\end{array}$ & $\begin{array}{c}6 \\
50 \\
7\end{array}$ & $\begin{array}{c}\text { Tenería } \\
\text { Beneficio } \\
\text { Condominios }\end{array}$ & $\begin{array}{c}2 \\
2 \\
7 / 9\end{array}$ \\
\hline $\begin{array}{l}\text { Montar campos } \\
\text { de cultivo para } \\
\text { los reactores }\end{array}$ & $\begin{array}{c}6 \\
3 \text { reactores } \\
\text { anaeróbicos } \\
3 \text { reactores } \\
\text { aeróbicos }\end{array}$ & $\begin{array}{c}2 \\
\text { c/muestra } \\
\text { Total }=12\end{array}$ & & & & \\
\hline
\end{tabular}

Fuente: La autora.

Partiendo del cuadro anterior una parte de las muestras líquidas fueron analizadas y otras fueron sometidas a tratamientos con reactores aerobios y anaerobios en el Laboratorio de Ingeniería Ambiental de la Escuela de Ingeniería Civil de la Universidad de Costa Rica (UCR). Los análisis físicos y químicos corresponden a sólidos, nitrógeno, fósforo, Demanda Química de Oxigeno (DQO), Demanda Biológica de Oxigeno (DBO), 
oxígeno disuelto, conductividad, temperatura y $\mathrm{pH}$, fueron realizados por el laboratorio de microbiología ambiental del Centro de Investigaciones Agronómicas (CIA) de la UCR.

Para el caso de los tiempos en los reactores estos se debieron a las condiciones del laboratorio y los periodos en los que se contaba con autorización para el ingreso y trabajo, por ello los tiempos varían, no obstante, se determinó que eso no debería de influir para las comparaciones de los resultados de los análisis mientras se garantizara que los reactores estuviesen en óptimas condiciones de funcionamiento, situación que se monitoreo constantemente durante el periodo de la investigación.

\section{Resultados}

Teniendo en cuenta que toda agua que sea utilizada para una actividad humana generará un residual, es que se tiene que prever que los subproductos de las actividades y los residuos de las mismas pueden generar aguas residuales de diferentes características, que deben de ser tratadas hasta alcanzar las características mínimas reguladas para devolverlas al medio a través de un cuerpo de agua, un sistema de alcantarillado o ser reutilizadas.

En cuanto a la generación de aguas residuales, se debe de considerar que, si no se le dan tratamientos adecuado dependiendo las características que tenga, estas aportaran una carga contaminante al medio, puesto que la condición del recurso que se devuelve al medio no tiene la misma calidad que antes de la actividad para la que se dispuso. (RVRAR, 2006)

Para los tres tipos de aguas residuales, se tomaron muestras de los efluentes generados de los tratamientos secundarios, esto porque en muchas de los sistemas de tratamiento del país ese es el último nivel al que se da tratamiento a las aguas residuales antes de verter al cuerpo de agua más cercano. Con el fin de realizar una comparación significativa de las características de los efluentes es que se requería muestras de aguas del mismo nivel de descontaminación.

Para el estudio se buscó tomar las muestras en el mismo nivel de tratamiento, esto a las salidas del sistema secundario, para que se pudiese hacer las comparaciones, es importante tomar en cuenta que el sitio del muestreo coincide con el agua que se vierte al cuerpo del agua.

A las muestras de los tres sistemas se analizaron las características físicas y químicas, que posteriormente se compararon con los límites recomendados por el Ministerio de Salud de Costa Rica (CUADRO 2.).

CUADRO 2.

Características físicas y químicas de las aguas residuales industriales y domésticos, San José

\begin{tabular}{ccccc}
\hline Parámetros & Tenería & Origen del efluente & Límites \\
\cline { 2 - 5 } & & & Doméstico & recomendados \\
\hline Físicos (mg/l) & 903 & 278 & 41 & $\begin{array}{c}\text { Tenería: } 150 \\
\text { Café: } 500 \\
* \text { Urbano: } 300\end{array}$ \\
\hline Sólidos totales & 445 & 252 & 33 & nd \\
\hline Sólidos filtrables & 458 & 26 & 8 & $\begin{array}{c}\text { Tenería: } 150 \\
\text { Café: } 500 \\
* \text { Urbano: } 300\end{array}$ \\
\hline $\begin{array}{c}\text { Sólidos suspendidos } \\
\text { o no filtrables }\end{array}$ & 146 & 30 & 0 & nd \\
\hline Sólidos volátiles & 2800 & 1111 & 325 & 250 \\
\hline Sólidos disueltos & 500 & 0,8 & 70 & 1 \\
\hline $\begin{array}{c}\text { Sólidos } \\
\text { sedimentables }\end{array}$ & 15 & 17 & 16 & $15-25$ \\
\hline Temperatura $\left({ }^{\circ} \mathrm{C}\right)$ & & & & \\
\hline
\end{tabular}




\begin{tabular}{|c|c|c|c|c|}
\hline \multirow{2}{*}{ Parámetros } & \multicolumn{3}{|c|}{ Origen del efluente } & \multirow{2}{*}{$\begin{array}{c}\text { Límites } \\
\text { recomendados }\end{array}$} \\
\hline & Tenería & Beneficio & Doméstico & \\
\hline \multicolumn{5}{|l|}{ Físicos (mg/l) } \\
\hline \multicolumn{5}{|c|}{ Químicos (mg/l) } \\
\hline $\mathrm{pH}$ & 10,21 & 8,01 & 9,09 & $6,5-7,5$ \\
\hline $\mathrm{OD}(\mathrm{mg} / \mathrm{l})$ & 4,24 & 0,88 & 0,57 & 8 \\
\hline $\mathrm{CD}(\mu \mathrm{s} / \mathrm{cm})$ & 5690 & 2400 & 682 & nd \\
\hline P total & 3,80 & 1,43 & 4,14 & $0,005-5$ \\
\hline $\mathrm{P}_{2} \mathrm{O}_{5}$ & 8,70 & 3,29 & 9,49 & $<25$ \\
\hline N-NH ${ }_{4}^{+}$ & 8,71 & 9,61 & 7,55 & 1,29 \\
\hline N-NH ${ }_{3}^{+}$ & 8,24 & 9,09 & 7,14 & 1,22 \\
\hline $\mathrm{N}-\mathrm{NO}_{3}^{-}$ & 5,20 & 18,00 & 13,50 & $<10$ \\
\hline $\mathrm{N}-\mathrm{NO}_{2}^{-}$ & 1575 & 0,75 & 0,00 & nd \\
\hline DQO & 270 & 1860 & 100 & 150 \\
\hline DBO & 452 & 695 & 180 & 50 \\
\hline
\end{tabular}

Fuente: Reglamento de Vertido y Reuso de Aguas Residuales, $\mathbf{N}^{\circ} 33601$

Elaborada por la autora.

*Vertido en alcantarillado Sanitario

En cuanto a los parámetros físicos, los sólidos analizados, se observa que las aguas del Beneficio de Café y el área residencial, cumplen con lo señalado, como se norma de forma específica según reglamento de vertido, mientras que las aguas de la Tenería exceden en 2,05 veces el límite permitido. Los Sólidos Sedimentables únicamente en las aguas del sistema del beneficio cumplieron; lo anterior indica un alto grado de contaminación por presencia de sólidos, lo que puede indicar que sin duda alguna es necesario uno o más proceso para mejorar la remoción de los sólidos, máxime que estos efluentes se disponen en los tres casos al cuerpo de agua más cercano. Únicamente en el caso de los procesos de tratamiento de la Tenería y el Beneficio después del punto de muestreo cuentan con un tratamiento adicional antes de verter al cuerpo receptor.

Según el Reglamente de Vertido y Reuso de Aguas Residuales, los parámetros químicos de fósforo y nitrógeno, se determinó que las lecturas del primero se encuentran por debajo de los límites recomendados y para el caso de los valores de nitratos las muestras del Beneficio y Condominio no cumplieron.

En el caso del nitrógeno amoniacal, todas las muestras de agua residual fueron superiores al valor recomendado, implicando contaminación como es de esperar dada la procedencia de los tipos de agua (específicamente reactores biológicos de las plantas). Pero los nitritos si se mantuvieron por debajo del término recomendado.

En cuanto a los parámetros bioquímicos, el agua residual procedente del Condominio se mantuvo por debajo del valor permitido en DQO, no así el agua residual analizada para el Beneficio y la Tenería superan en 11,4 y 0,8 veces respectivamente el valor permitido de $150 \mathrm{mg} / \mathrm{L}$, para el caso de la demanda biológica el DBO, es importante mencionar que al momento de la investigación los sistemas se encontraban en condiciones óptimas de operación.

- Parámetros Físico-Químicos, de los reactores anaerobios y aerobios del laboratorio.

De las muestras que se tomó en campo de cada una de los tres sistemas de tratamiento, se dispuso en condiciones de laboratorio en un reactor anaerobio y uno aerobio, por diferentes periodos de cultivos para homogeneizar las condiciones de las aguas, posterior al tiempo de las muestras en los reactores se les realizaron análisis de los siguientes parámetros: $\mathrm{pH}$, conductividad, oxígeno disuelto y sólidos disueltos, con el fin de determinar el funcionamiento de los reactores. 
Los resultados de los análisis de las muestras de los reactores se detallan en el CUADRO 3., donde es importante mencionar que los valores de $\mathrm{pH}$, para todos los reactores se mantuvo en los rangos necesarios para el crecimiento bacteriano de 6,5 a 9,5. (Vargas, 2010)

El oxígeno disuelto en las aguas de los reactores aerobios mejoró, a diferencia de los reactores anaerobios de las aguas del Condominio y el Beneficio que disminuyeron por debajo de 1 , sin embargo, la muestra del reactor anaerobio de la Tenería registro un valor no tan alto como el de la muestra del sitio, pero lo suficiente para el crecimiento de bacterias.

En el caso de la conductividad, disminuyeron los valores registrados, en la mayoría de las muestras de los reactores implicando una tendencia a la descontaminación, no obstante, en el reactor anaerobio del Condominio a los 7 días registró una lectura superior a la se la muestra del sitio.

Por último, todos los valores de sólidos disueltos, que se registraron fueron inferiores a los de las muestras de aguas residuales que venían directamente del sitio, porque, se puede afirmar que se descontaminó, en algún porcentaje las aguas de los reactores del laboratorio. 


\section{CUADRO 3}

Resultados de los Parámetros Químicos: OD y Conductividad y los Parámetros Físicos de Temperatura y aerobio

\begin{tabular}{|c|c|c|c|c|c|c|c|c|c|c|c|}
\hline Sitio & \multicolumn{2}{|c|}{ Tenería } & \multirow[b]{2}{*}{$\begin{array}{c}\text { Reactor } \\
\text { Aerobio } \\
2 \text { días } \\
\end{array}$} & \multicolumn{3}{|c|}{ Beneficio } & \multicolumn{4}{|c|}{ Condominios } & \multirow{3}{*}{ Unidades } \\
\hline Parámetros & $\begin{array}{c}\text { Reactor } \\
\text { Anaerobio } \\
6 \text { días }\end{array}$ & $\begin{array}{c}\text { Reactor } \\
\text { Aerobio } \\
2 \text { días } \\
\end{array}$ & & $\begin{array}{c}\text { Reactor } \\
\text { Anaerobio } \\
50 \text { días }\end{array}$ & $\begin{array}{c}\text { Reactor } \\
\text { Aerobio } \\
2 \text { días } \\
\end{array}$ & $\begin{array}{c}\text { Reactor } \\
\text { Aerobio } \\
2 \text { días } \\
\end{array}$ & $\begin{array}{c}\text { Reactor } \\
\text { Anaerobio } \\
7 \text { días } \\
\end{array}$ & $\begin{array}{c}\text { Reactor } \\
\text { Aerobio } \\
9 \text { días }\end{array}$ & $\begin{array}{c}\text { Reactor } \\
\text { Aerobio } \\
9 \text { días }\end{array}$ & $\begin{array}{c}\text { Reactor } \\
\text { Aerobio } \\
7 \text { días } \\
\end{array}$ & \\
\hline pH & & Sin Filtrar & Filtrada & & Sin Filtrar & Filtrada & & Filtrada & Sin Filtrar & Sin Filtrar & \\
\hline Temperatura & 20,6 & 20,9 & 20,9 & 20,8 & 19,7 & 19,6 & 20,5 & 19,4 & 19,5 & 20,3 & ${ }^{\circ} \mathrm{C}$ \\
\hline Medición & 8,06 & 7,47 & 7,86 & 8,2 & 7,89 & 7,64 & 8,26 & 8,27 & 7,88 & 7,82 & \\
\hline $\begin{array}{l}\text { Oxígeno } \\
\text { Disuelto } \\
\end{array}$ & & & & & & & & & & & \\
\hline Temperatura & 21 & 21,3 & 21,1 & 20,7 & 19,2 & 19,4 & 21 & 19,2 & 19,5 & 20,4 & ${ }^{\circ} \mathrm{C}$ \\
\hline Medición & 3,32 & 3,12 & 4,76 & 0,67 & 5,93 & 5,68 & 0,305 & 6,11 & 6,55 & 5,11 & $\mathrm{mg} / \mathrm{l}$ \\
\hline Conductivida & & & & & & & & & & & \\
\hline Temperatura & 20,5 & 20,8 & 20,8 & 21,4 & 19,8 & 19,9 & 20,7 & 19,3 & 19,6 & 20,2 & ${ }^{\circ} \mathrm{C}$ \\
\hline Medición & 5510 & 547 & 613 & 1936 & 1296 & 1364 & 690 & 675 & 679 & 648 & $\mathrm{us} / \mathrm{cm}$ \\
\hline $\begin{array}{c}\begin{array}{c}\text { Sólidos Totale } \\
\text { Disueltos }\end{array} \\
\end{array}$ & & & & & & & & & & & \\
\hline Temperatura & 19,7 & 20,3 & 19,9 & 20,3 & 19,1 & 18,9 & 20,6 & 18,5 & 18,7 & 19,2 & \\
\hline Medición & 2630 & 243 & 304 & 925 & 343 & 365 & 305 & 314 & 280 & 311 & $\mathrm{mg} / \mathrm{l}$ \\
\hline
\end{tabular}




\section{- Parámetros Microbiológicos}

El propósito del proyecto de investigación fue la búsqueda de una base en la identificación de los microorganismos para determinar cuáles de ellos coincidían, en todas las muestras de aguas residuales tanto de los reactores en el laboratorio como de las muestras directamente de las plantas de tratamiento, para así poder comparar los rendimientos de desinfección.

En total se trabajó con 18 campos de cultivo de los tres tipos de muestra en condiciones de campo, de laboratorio con filtro de los reactores y sin filtro en diferentes tiempos de proceso, como se indica en los Cuadros 4, 5 y 6 . Para ello se usó el método de características fenotípicas, para el aislamiento e identificación de los tipos de bacteria presente.

De los análisis de cultivo de bacterias se determina que para las tres diferentes tipos de aguas residuales únicamente la bacteria pseudomonas taetrolens, fue la coincidente; también observa que de las quince bacterias identificadas siete de ellas son de la misma familia, de pseudomonas y comparten características similares en cuanto al comportamiento que tienen a lo largo de los procesos de descontaminación, además la mayoría de las cuantificaciones fueron superiores para las bacterias de procedencia aerobia. Estas bacterias se pudieron ver asociadas al proceso de tratamiento de origen de cada una de las aguas.

CUADRO 4.

Resultados microbiológicos del Beneficio

\begin{tabular}{|c|c|c|c|c|}
\hline \multicolumn{5}{|c|}{ Beneficio } \\
\hline Fecha & Prueba & Muestra & Bacteria & Cantidad \\
\hline \multirow{2}{*}{$17 / 04 / 2009$} & \multirow{2}{*}{ Reactor aerobio } & Filtrada & Pseudomonas sp & - \\
\cline { 3 - 5 } & & Sin Filtrar & Comamonas Testosteroni & - \\
\hline $15 / 05 / 2009$ & Reactor anaerobio & 50 días & Pseudomonas fluorescens & 95000000 \\
\hline \multirow{2}{*}{$06 / 03 / 2009$} & \multirow{2}{*}{ Sitio } & Aerobia & Pseudomonas taetrolens & 110000000 \\
\cline { 3 - 5 } & & Anaerobia & Leuconostoc mesenteroides & 24000000 \\
\hline
\end{tabular}

Fuente: Resultados de las pruebas del Laboratorio, modificado por la autora.

CUADRO 5.

Resultados microbiológicos de la Tenería

\begin{tabular}{|c|c|c|c|c|}
\hline \multicolumn{5}{|c|}{ Tenería } \\
\hline Fecha & Prueba & Muestra & Bacteria & Cantidad \\
\hline \multirow{2}{*}{$06 / 03 / 2009$} & Reactor anaerobio & Anaerobia & Pseudomonas aeruginosa & 17000 \\
\cline { 3 - 5 } & 16 días & Aerobia & Pseudomonas aeruginosa & 7000000 \\
\hline \multirow{2}{*}{$06 / 03 / 2009$} & \multirow{2}{*}{ Sitio } & Aerobia & Pseudomonas taetrolens & 6800000 \\
\cline { 3 - 5 } & & Anaerobia & Pseudomonas taetrolens & 870000 \\
\hline $03 / 04 / 2009$ & Reactor anaerobio & 40 días & Citrobacter sp, & 930000 \\
\hline \multirow{2}{*}{$31 / 3 / 20009$} & \multirow{2}{*}{ Reactor aerobio } & Filtrada & No identificada & 610000 \\
\cline { 3 - 5 } & & Sin Filtrar & Pseudomonas marginalis & 12000000 \\
\hline
\end{tabular}

Fuente: Resultados de las pruebas del Laboratorio, modificado por la autora.

CUADRO 6.

Resultados microbiológicos del Condominio

\begin{tabular}{|c|c|c|c|c|}
\hline \multicolumn{5}{|c|}{ Condominio } \\
\hline Fecha & Prueba & Muestra & Bacteria & Cantidad \\
\hline \multirow{2}{*}{$06 / 03 / 2009$} & \multirow{2}{*}{ Sitio } & Aerobia & Vibrio tubiashii & 1200000000 \\
\hline & & Anaerobia & Pseudomonas taetrolens & 1400000 \\
\hline \multirow{2}{*}{$06 / 06 / 2009$} & \multirow{2}{*}{ Reactor aerobio } & Sin Filtrar & $\begin{array}{c}\text { Pandoraea norimbergensis } \\
\text { Vibrio cincinnatiensis }\end{array}$ & 25000000 \\
\hline & & Filtrada & $\begin{array}{c}\text { Ochrobactrum anthropi } \\
\text { Pseudomonas maculicola }\end{array}$ & 490000 \\
\hline
\end{tabular}




\begin{tabular}{|c|c|c|c|c|}
\hline \multicolumn{5}{|c|}{ Condominio } \\
\hline Fecha & Prueba & Muestra & Bacteria & Cantidad \\
\hline & $\begin{array}{c}\text { Reactor } \\
\text { anaerobio }\end{array}$ & 7 días & $\begin{array}{c}\text { Klebsiella oxytoca } \\
\text { Ochrobactrum anthropi }\end{array}$ & 84000 \\
\hline $31 / 03 / 2009$ & $\begin{array}{c}\text { Reactor } \\
\text { anaerobio }\end{array}$ & 35 días & Brevundimonas diminuta & 17000 \\
\hline
\end{tabular}

Fuente: Resultados de las pruebas del Laboratorio, modificado por la autora.

\section{Discusión}

La identificación de microorganismos en los tipos de aguas residuales es una tendencia innovadora que busca acelerar los procesos de descontaminación en las aguas residuales que se vierten a un cuerpo de agua, para el caso de los tres tipos de aguas residuales tanto de los sistemas como de los reactores analizadas la coincidencia de un microorganismo y la coincidencia de las familias de siete de las especies identificadas, es alentador con el propósito de tratar de estandarizar recomendaciones en cuanto al funcionamiento, mantenimiento y mejoras en los sistemas de descontaminación de las plantas de tratamiento en general. (Vargas, 2010)

Las pseudomonas taetrolens, miembros de la familia de las pseudomonas, se caracterizan por tener: formas alargadas, de longitud cortas a medias, gram-negativas (se tintura de color rosa en la prueba Gram), móviles por medio de un flagelo polares (un solo flagelo o un penacho o grupo de flagelos); no esporulada (no forma esporas), aerobios y heterótrofos. Muchas veces esta pseudomona es conocida como la bacteria de barra que causa el moho en los huevos. (Pinzón-Junca, 2019)

En particular, para la muestra del Beneficio, este microorganismo se encontró en medio aerobio; en el caso de las aguas del Condominio, esta bacteria estuvo presente en medio anaerobio únicamente; sin embargo, para las muestras de la Tenería, esta pseudomona estuvo tanto en condición anaerobia como aerobia. Por último, de todas las aguas que se analizaron, la coincidencia de la bacteria se dio únicamente en las muestras de aguas residuales que venían directamente de los reactores biológicos de los sistemas de tratamiento, no se encontró coincidencia en las aguas analizadas en los reactores.

Una vez que se han comparado los resultados de las pruebas físico-químicas, con la norma costarricense, se ha podido determinar que el agua no está en condiciones para que se pueda verterse a un alcantarillado sanitario o a un cuerpo de agua, al compararse también literaturas como el Atlas de Ecología microbiana y microbiología ambiental (Ronald et al., 2002), así como Manuales de clínica Microbiológica (Murray et al., 2005); se puede confirmar con certeza que el agua residual de las muestras tratada en los reactores biológicos de cada planta de tratamiento está lejos de los parámetros de normas y no es segura para verterse.

A pesar de lo antes mencionado, hay que rescatar que algunas de las muestras de agua residuales cumplieron con algunos parámetros, como se observa en los CUADRO 2.; en el caso de los sólidos suspendidos y sedimentables, las aguas del Beneficio cumplieron muy por debajo de la norma, a diferencia de las aguas del Condominio y la Tenería; Por otra parte, son indicadores de gran contaminación la cantidad de nitrógeno amoniacal, amonio, amoniaco, fosfatos y nitratos que se observaron en cada una de las lecturas de las pruebas que se realizaron a las muestras de agua.

De las pruebas de DBO y DQO, se puede concluir que debido a los altos valores registrados (CUADRO 3.), hay una gran concurrencia de bacterias, lo cual implica la necesidad de oxígeno para poder estabilizar las poblaciones de microorganismos, puede ser recomendable en otra investigación el verificar la biodegradabilidad de las aguas para compararlo con el crecimiento microbiano; para el caso de la investigación 
es determinante mantener una adecuada aireación de los diferentes tipos de agua residual que se trate, dado que esto ayuda a mantener la distribución de bacterias a lo largo del área de los tanques y de esta manera se puede agilizar los procesos de eliminación de agentes contaminantes y para el caso de sistemas de tratamientos de aguas residuales con procesos anaerobios, se debe de incrementar los microorganismos que pueden sobrevivir con respiración anaerobia y favorezcan la eliminación de contaminantes de las aguas.

Habiendo reconocido de forma hipotética la gran cantidad de microorganismos, con los resultados de las pruebas mencionadas anteriormente esto se confirmó, en los cultivos microbiológicos que se realizaron a las muestras de aguas residuales, y fue posible identificar quince diferentes tipos de bacterias de la población predominante en los platos de cultivo; para cada caso de agua, las bacterias que estuvieron en mayor proporción fueron las aeróbicas; lo que coincide con la respiración de la mayoría de los microorganismos que son del tipo gram-negativo. (Marchand, 2002).

Con los resultados de las pruebas microbiológicas, se pudo concluir que solo una de las bacterias fue coincidente en los tres diferentes tipos de aguas residuales, la pseudomonas taetrolens, perteneciente a la familia de las pseudomonas. Por ello se recomienda incrementar el crecimiento y desarrollo de estas bacterias, ya que pueden ayudar a los procesos de nitrificación; además son resistentes a condiciones adversas y tienen la capacidad de garantizar con mayor seguridad el no perder el funcionamiento del tratamiento de descontaminación, en caso de una eventualidad que perjudique las condiciones del medio donde se lleve a cabo el proceso. Además, son capaces de degradar materia tóxica del agua, sin sufrir cambios en las propiedades de su estructura. (Sternberg et al., 2021)

Como se trabajó con tres tipos de aguas residuales, las poblaciones bacterianas son muy diferentes, además de que únicamente se identificó la bacteria de la sepa predominante de los platos de cultivo; no obstante, algunas de las bacterias encontradas tienen la capacidad de desarrollarse en medios muy diversos, por lo que se podrían encontrar en casi cualquier tipo de agua residual.

En el agua del Beneficio se identificaron tres tipos de bacterias: las pseudomonas sp, las pseudomonas florenscens y las pseudomonas taetrolens; del agua de la Tenería se identificaron tres tipos: pseudomonas aeruginosa, pseudomonas taetrolens y pseudomonas marginalis; por último, para el agua del Condominio, a pesar de ser el agua con mayor diversidad de microorganismos, únicamente se identificaron la pseudomona taetrolen y la pseudomona maculicula.

Es importante mencionar que, a pesar de ser diferentes tipos de pseudomonas, al ser parte de la misma familia, poseen características similares en cuanto a degradación de agentes contaminantes; sin embargo, en la actualidad, solamente de la pseudomonas aeruginosa es posible saber a ciencia cierta la capacidad de degradar que posee, dada la diversidad de estudios que se han hecho con esta especie; para el resto de tipos de pseudomonas, es vasta la información en cuanto al daño que le pueden causar a los seres vivos si llegan a estar infectados con ellas, pero no sobre el impacto ambiental que genera el hecho de que estén presentes en suelos y aguas. (Panicura, 2020)

Para que la descontaminación de las aguas residuales tenga lugar, los microorganismos utilizados deben presentar una actividad adecuada; para lograrlo, se deben generar las condiciones ambientales óptimas (nutrientes, temperatura, oxígeno, etc,) que favorezcan el crecimiento de la población de microorganismos. Esto a su vez, provocará un aumento en la velocidad de biodegradación de los compuestos contaminantes, y con ello la destoxificación de las aguas o el medio. Además, el mantener microorganismos en los sistemas de descontaminación ayuda, específicamente en procesos como la coagulación, floculación, sedimentación y filtración. La Klebsiella (microorganismo identificado en aguas de las muestra del Condominio), se determina que colonizan con frecuencia en las superficies a lo interno de las tuberías de agua potable y se reproducen 
dentro de los tanque de almacenamiento muchas veces se le conoce como rebrote y crecen formando una biopelícula cuando las condiciones son favorables, en otras palabras, por la existencia de nutrientes, temperaturas cálidas, bajas concentraciones de desinfectantes y largos tiempos de retención en el almacenamiento, favorecen procesos como los antes mencionados, hasta incluso la desinfección del agua. (López et al., 2017).

\section{Conclusiones}

Debido a que no fue posible la coincidencia en más de un microorganismo entre las aguas de las tres diferentes plantas de tratamiento, se concluye que no se puede estandarizar recomendaciones en cuanto a operación y sistemas específicos del proceso de descontaminación de las diferentes aguas residuales, para incrementar o disminuir el crecimiento de microorganismos específicos; no obstante, es evidente que las plantas de tratamiento cuentan con un buen funcionamiento y cumplen con los parámetros físico-químicos que la norma costarricense regula.

Costa Rica no cuenta con la normativa suficiente que regule los contenidos de nutrientes dentro del Reglamento de Vertido y Reuso de Aguas Residuales, de parámetros físico-químicos como el nitrógeno y fósforo en los efluentes o de bacterias que no sean únicamente coliformes; no obstante, se espera que en un futuro cercano estos y otros parámetros se incluyan dentro de la normativa, para ayudar a mejorar la calidad de los cuerpos receptores de las aguas y disminuir la contaminación tanto de cursos de agua, como de mantos acuíferos. Para futuras investigaciones se recomienda seleccionar parámetros microbiológicos e incluirlos en los sistemas de tratamiento de agua.

Es de esperar que con tantos avances tecnológicos se logren implementar sistemas que favorezcan de mayor forma la descontaminación de las aguas residuales que se produzcan de diferentes procesos industriales o domésticos; sin embargo, las plantas que operan hoy deben mantener un control periódico y constante de las condiciones de funcionamiento y de los parámetros de control de contaminantes que regule la normativa nacional, para garantizar que el agua que se vaya a verter después de recorrer los sistemas de tratamiento, no afectará en gran medida el ambiente.

Por último, se recomienda un estudio microbiológico pretinen por tipo de agua para así determinar los grupos de microorganismos, partiendo de ellos se puede escoger que tipo de microorganismos probar para mejorar la calidad del agua de vertido.

\section{Referencias}

Allen, M. (1996). La Importancia para la Salud pública de los indicadores bacterianos que se encuentran en el agua potable. Reunión sobre la calidad del Agua Potable. CEPIS. OPS. OMS. Lima, Perú.

López, T. \& Vargas, D. (2017, diciembre). Uso de microorganismos eficientes para tratar aguas contaminadas. Ingeniería Hidráulica y Ambiental. Volumen 38 (No. 3).

Marchand, O. (2002). Microorganismos indicadores de la calidad del agua de consumo humano en Lima Metropolitana. (Tesis de Licenciatura). Universidad Nacional Mayor de San Marcos. Facultad de Ciencias Biológicas. EAP. de Ciencias Biológicas.

Murray, R. \& Baron, J. (2005). Manual of Clinical Microbiology. ASM PRESS, Washington, D.C. 
Paniura, R. (2020). Atlas de microorganismos. ACRIBD. Recuperado 21 de junio de 2021, de https://es.scribd.com/doc/97086700/Atlas-de-Microorganismos. 1-26 p.

Pinzón-Junca A. (2019, marzo). Pseudomonas. Scientific electronic library online. Acta Medica Colombiana. Volumen 44 (No.1).

Programa Educativo. (2004). Biorremediación: Biotecnología y limpieza del medio ambiente. El Cuaderno de Porque Biotecnología. Edición N. a 46. 1-14 p.

Reglamento de Vertido y Reuso de Aguas Residuales [RVRAR], № 33601. Última versión de la norma. Artículos 1 al 71. Fecha de promulgación 09 de agosto de 2006 (Costa Rica)

Rodríguez, D. (2002). Evaluación físico-química del sistema de tratamiento de aguas residuales. (Tesis inédita de Licenciatura). Universidad de Costa Rica, San José, Costa Rica. 39 p.

Ronald M.; Bartha, Richard. (2002). Ecología microbiana y microbiología ambiental. Madrid (España). Pearson-Addison Wesley. $677 \mathrm{p}$.

Sternberg, M. \& Lockwood, L. (2021, febrero). Oxidation of Isomaltose by Pseudomonas taetrolens. American Society for microbiology. Jornal of Bacteriology. Volumen 99 (No. 2).

Vargas, C. (2010). Análisis de bacterias comunes en plantas de tratamientos de diferentes efluentes que son indicadores de alta eficiencia en remoción de contaminantes. (Proyecto de Graduación para optar por el grado académico de licenciada en Ingeniería Civil). Universidad de Costa Rica. Facultad de Ingeniería. Escuela de Ingeniería Civil. San José, Costa Rica. 74 - 112 p.

Vidal, P. (2006) Aireación aplicada a los requerimientos de la flora microbiana como herramienta para inducir nitrificación y desnitrificación en plantas de tratamiento de aguas residuales. (Tesis inédita de Licenciatura). Universidad de Costa Rica, San José, Costa Rica. 65-95 p. 